\title{
Erratum zu: Treasury in Unternehmen der Sozialwirtschaft
}

Bernd Schubert und Hartmut Clausen

\section{Erratum zu: \\ B. Schubert und H. Clausen (Hrsg.), Treasury in Unternehmen der Sozialwirtschaft, Sozialwirtschaft innovativ, https://doi.org/10.1007/978-3-658-20311-5}

Folgende Abbildungen wurden in verbesserter Qualität gedruckt: S. 26 (Abb. 3), S. 31 (Abb. 7), S. 189 (Abb. 1), S. 191 (Abb. 2), S. 263-265 (Abb. 1-3), S. 296 (Abb. 1).

Die korrigierten Versionen der Kapitel sind verfügbar unter https://doi.org/10.1007/978-3-658-20311-5_2

https://doi.org/10.1007/978-3-658-20311-5_12

https://doi.org/10.1007/978-3-658-20311-5_17

https://doi.org/10.1007/978-3-658-20311-5_18

(C) Springer Fachmedien Wiesbaden GmbH, ein Teil von Springer Nature 2019 